\title{
Reseña de Un mar de ciència i coneixement. Els seguiments científics del medi marí a Menorca
}

\author{
Review of Un mar de ciència i coneixement. \\ Els seguiments científics del medi marí a Menorca
}

\author{
Francesc Xavier Roig-Munar ${ }^{1}$
}
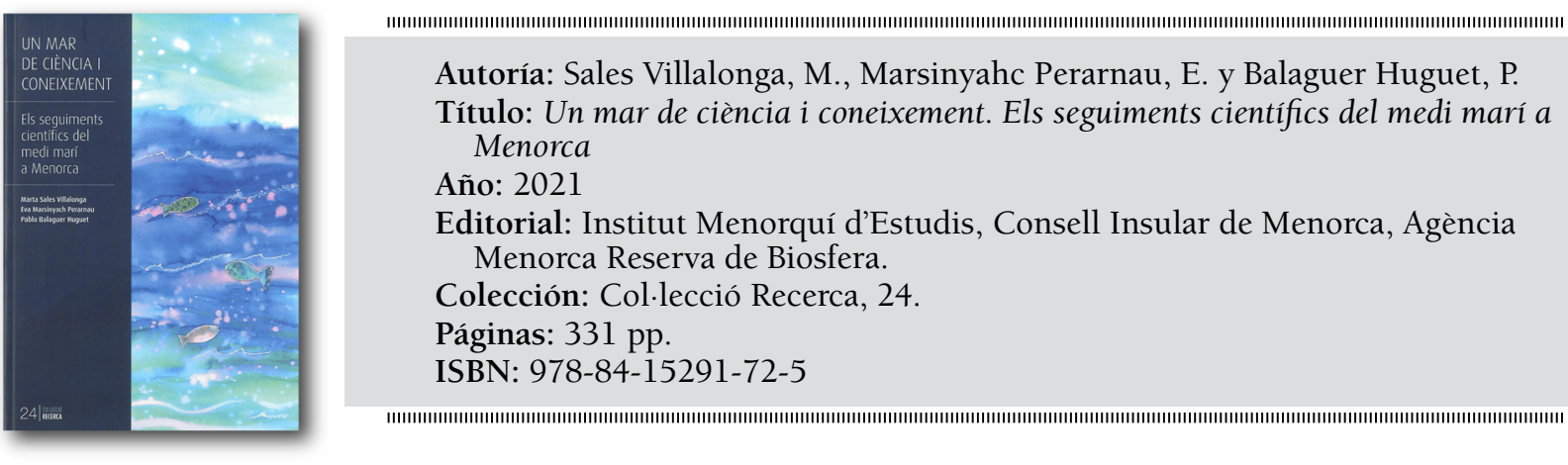

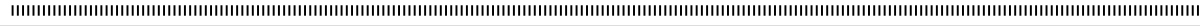

Autoría: Sales Villalonga, M., Marsinyahc Perarnau, E. y Balaguer Huguet, P.

Título: Un mar de ciència i coneixement. Els seguiments científics del medi marí a Menorca

Año: 2021

Editorial: Institut Menorquí d'Estudis, Consell Insular de Menorca, Agència Menorca Reserva de Biosfera.

Colección: Col-lecció Recerca, 24.

Páginas: $331 \mathrm{pp}$.

ISBN: 978-84-15291-72-5

El espacio marino y litoral de Menorca ha sido el ámbito menos estudiado y analizado, muy a pesar de ser el más promocionado y reclamado. En este libro, Un mar de ciència i coneixement. Els seguiments científics del medi marí a Menorca, se encuentra una extensa y rica recopilación de la información existente sobre los seguimientos del medio marino y litoral. Información que permite conocer mejor el mar que nos rodea y su perímetro terrestre, así como la situación de las diferentes especies y hábitats marinos, y su relación con el hombre para hacer una gestión desde el conocimiento. Tradicionalmente la fauna marina de Menorca había sido estudiada a finales del s. XIX por el botánico Joan Joaquín Rodríguez, con una buena descripción de herbarios de algas. Actualmente se puede decir que en los últimos 120 años la variación ha sido escasa, hecho que informa de la calidad de los fondos marinos de la isla.

A la pregunta, ¿Qué se sabe de la investigación marina de los últimos veinte años en Menorca?, el libro Un mar de ciència i coneixement. Els seguiments científics del medi marí a Menorca pretende llenar el vacío de la literatura litoral y marina de la isla. Se ha realizado una importante compila- ción de los principales estudios y seguimientos realizados en los ecosistemas marinos y litorales. El libro se configura como una base de referencia o indicador para detectar cambios y posibles actuaciones de gestión. La exhaustiva recopilación de la información sobre los seguimientos del medio marino (estudios, informes e investigaciones), permite conocer qué pasa en el medio litoral que nos rodea, la situación de especies y hábitats, sus usos y explotaciones, en aras de hacer una gestión desde el conocimiento. La reciente ampliación de la Reserva de Biosfera hacia el mar, la creación de una nueva reserva marina, y la futura protección marina de la zona del Parque Natural de es Grau, pone en la agenda de Menorca el reto de conservar un mar sin que esto suponga el sacrificio de sus usos y explotación.

El libro expone una situación crítica a corto plazo, donde el desarrollo del modelo litoral de los últimos 50 años está en decadencia, basado en el turismo de sol y playa, y con escasa movilidad de los visitantes. Actualmente el nuevo turismo, con auge de las actividades recreativas marinas, asociadas al turismo residencial, y un incremento de la restauración de proximidad, supone una mayor

1 Consultor Ambiental. Dr. en Geografía y Dr. en Geología. C/ Carritxaret, 18 - 6, 07749, es Migjorn Gran, Menorca, España. xiscoroig@ gmail.com 
presión sobre el medio litoral y marino. Medios que hasta ahora no recibían tanta presión y no disponían, ni disponen, de regulación efectiva en toda su extensión. Es por esto que cabe un planteamiento de ordenación y regulación de los usos en el litoral y sus aguas interiores, siendo el libro una buena base de partida. En este libro se permite, a pesar de estar en una isla con un modelo de turismo maduro, no partir del escenario cero, ya que recopila abundante información adquirida en los últimos 25 años. El libro facilita focalizar la gestión basada en la investigación y en el análisis de sus resultados, y no en la simple promoción turística sin evaluación de las consecuencias, como sucede actualmente.

Los capítulos que conforman el libro, 14 en total, abarcan todo el abanico del medio, desde una breve historia de la investigación marina de la isla, como antecedentes de los resultados que sirven de base actual para establecer el punto de partida. Se analiza también la evolución de los espacios naturales marinos de la isla, con una cartografía detallada de cada uno de ellos, pasando de $6.846 \mathrm{Ha}$ protegidas en 1999 a $631.690 \mathrm{Ha}$ en 2019. Otros capítulos exponen el medio físico-químico y la biodiversidad bentónica y de fondos marinos, con su contextualización geológica y morfológica. Destaca el capítulo dedicado a las fanerógamas como ecosistemas estructurantes de diversas comunidades de organismos que presentan elevada biodiversidad. Estas fanerógamas tienen gran trascendencia sedimentológica, básica para el mantenimiento de las morfologías de sistemas playa-duna. Otros capítulos importantes son los dedicados a la fauna; invertebrados, peces, aves marinas, así como tortugas y mamíferos, su relación con el medio y con las presiones. Dentro de esta temática destaca el capítulo dedicado a las especies invasoras del litoral, tratándose de uno de los principales cambios que sufren los ecosistemas, asociado a la interna- cionalización del transporte marítimo, al cambio climático, o al papel de la suelta incontrolada de estas especies por parte del ser humano, no solo en la isla, sino dentro del ámbito de la cuenca mediterránea. Al capítulo de actividades y presiones, le preceden 12 capítulos básicos para entender el estado actual del medio litoral. Las actividades y presiones son ampliamente analizadas; contaminación de aguas, calidad ecológica, presión náutico-recreativa y presión humana en los sistemas playa-duna. También se analiza su explotación, sus usos turísticos y recreativos, así como la pesca recreativa, mientras que los usos profesionales son analizados mediante apartados de pesca profesional. Dentro de estas presiones destaca el grado de urbanización litoral, como factor de antropización, presión y alteración. Por último, el capítulo 14 realiza una extensa reflexión, basada en los datos recopilados, acerca del futuro del medio litoral de la isla, con una aproximación al crecimiento que han seguido los espacios naturales y sus usos actuales. Así mismo, se reflexiona sobre la relación con el cambio climático, ya que al tratarse de un espacio mediterráneo éste es uno de los mares más amenazados en todos los sentidos.

Por ende, el libro es un buen compendio del estado del litoral de la isla, previo y actual, con buenos datos de evoluciones y tendencias en cada unos de los capítulos tratados. El ejemplar se configura como una base de datos sólida para regular y ordenar los futuros usos ante las más que evidentes amenazas. Aún así este libro, editado por la administración pública, y editado únicamente en soporte papelero, tiene un coste excesivo al ser un compendio de trabajos realizados desde una administración pública o con fondos públicos. A pesar de ello, se trata de una buena herramienta en la futura planificación, gestión y ordenación o reordenación del medio marino y litoral, en incluso en su posible deconstrucción. 